REVESCO. Revista de Estudios Cooperativos

ISSN: $1885-8031$

https://dx.doi.org/10.5209/REVE.73861

\title{
Escalas salariales en la economía del bien común
}

\author{
José Manuel Sastre Centeno ${ }^{1}$ y Elena Inglada Galiana ${ }^{2}(0$ \\ Recibido: 8 de noviembre de 2019 / Aceptado: 20 de octubre de 2020 / Publicado: 15 de febrero de 2021
}

Resumen. El sistema económico capitalista, desde el comienzo de su historia, no ha estado exento de teorías y pensamientos críticos que han puesto sobre la mesa sus dificultades e imposibilidades en ciertos aspectos. La presente economía capitalista lleva para muchos, aparte de una crisis monetaria, repercusiones en otros contextos (impacto ecológico, energético, crisis social, alimentaria, etc.). Si bien, se han ido forjando, desde hace años, otros tipos de alternativas y más recientemente la Economía del Bien Común, un proyecto económico que pretende crear los incentivos con los cuales la actividad económica se dirija hacia el Bien Común, es decir, fomentar los valores humanos de la solidaridad, dignidad, sostenibilidad, justicia social, democracia y transparencia, recuperando el concepto de éxito económico y vinculándolo hacia el beneficio social. El modelo de la EBC plantea el uso de unas premisas e indicadores para conformar unas escalas salariales justas, siendo éste el objeto de estudio del presente trabajo, junto con el análisis de dos de los valores fundamentales del modelo y su contribución a ambos, la equidad y justicia social.

Palabras clave: Economía social; Crisis económica; Modelo económico del bien común; Diferencias salariales.

Claves Econlit: L39; P47; O35.

\section{[en] Salary scales in the common good economy}

\begin{abstract}
Since its beginnings, the capitalist economic system, has not been exempt from theories and critical thoughts that have put on the table its difficulties and impossibilities in certain aspects. Many thinkers believe that the present capitalist economy has, aside from monetary crisis, repercussions in other contexts (ecological, energy, social, food crisis, etc.). Other types of alternative economies have appeared along since the capitalist system, such as, recently, the Economy of the Common Good, an economic project that aims to create incentives in which economic activity is directed towards the Common Good. This economy tries to promote human values of solidarity, dignity, sustainability, social justice, democracy and transparency, recovering the concept of economic success and linking it to social benefit. The use of the premises that the EBC proposes to conform salary scales and fair remuneration is analyzed, together with the contributions and indicators of the two fundamental model's values; equity and social justice.
\end{abstract}

Keywords: Social economy; Economic crisis; Economic model of the common good; Difference between salaries.

Sumario. 1. Introducción. 2. a economía de bien común: un modelo alternativo. 3. Los beneficios de la EBC y la Responsabilidad Social Empresarial (RSE). 4. La propuesta de la EBC en las escalas salariales. 5. Resumen y conclusiones. 6. Referencias bibliográficas.

Cómo citar. Sastre Centeno, J.M.; Inglada Galiana, E. (2021) Escalas salariales en la economía del bien común. REVESCO. Revista de Estudios Cooperativos, vol. 137, e73861. https://dx.doi.org/10.5209/reve.73861.

\section{Introducción}

La sociedad, tras la crisis financiera mundial de 2008 y sus consecuencias, ha reaccionado ante las desigualdades sociales e irregularidades realizadas en el contexto político y empresarial. A partir de todo esto, han surgido otros tipos de economías y una de ellas es la Economía del Bien Común (EC). Ésta intenta solventar las injusticias que el modelo imperante ha ido creando durante los años y otorgar la relevancia a los valores del ser humano, desplegando un patrón económico cuyas bases esenciales son los valores morales y la dignidad de las personas. Todo ello puede y debería ser aplicado a las organizaciones y a sus grupos de interés. La importancia de la EBC es que además de un modelo económico viable se ha convertido en un vasto movimiento a nivel mundial con miles de empresas, de personas y comunidades que participan, despliegan y la implementan. Hoy en día, existen en Europa, Norteamérica y Latinoamérica alrededor de dos

1 Universidad de Valladolid, España.

Dirección de correo electrónico: manolo@eco.uva.es.

2 Universidad de Valladolid, España.

Dirección de correo electrónico: elenaig@eco.uva.es. 
mil empresas establecidas en 30 países mediante asociaciones gestionadas por la sociedad civil e implantación de este modelo económico (Campos, Sanchis y Ejarque, 2019).

Las ideas y principios de este sistema económico surgen en el continente europeo en el momento de la Revolución Industrial en forma de réplica a la progresiva pauperización de la clase obrera. No obstante, fue el profesor, economista y activista austríaco Christian Felber, el encargado de propagar este modelo económico al albor de la crisis referida. La EBC es la expresión de un nuevo modelo económico sostenible que emplaza en el centro de la actividad económica al ser humano y a todos los seres vivos, y al funcionamiento de las relaciones entre ellos (Foti et al., 2017).

Frente al capitalismo y consumismo, las empresas que se acogen a la EBC son más eficientes, favorecen a otras organizaciones y crean más beneficios para la sociedad. En 2011, el modelo empieza a introducirse en el contexto empresarial (Compés López y Asensio Calatayud, 2014). El dinero y el crecimiento no han de ser fines en sí mismos, sino las herramientas para conseguir el objetivo real de esta economía, que no es otro que la calidad de vida de la comunidad y su bienestar. Una organización si cubre las necesidades básicas con los sueldos de sus empleados será exitosa, y eso se consigue estableciendo unas escalas salariales justas y equitativas. La EBC, por ejemplo, plantea que dentro de una empresa el salario mayor no debe ser mayor de 10 veces al salario más reducido. Y además el salario máximo y el mínimo están destinados a ser límites legales, si bien, en los que se encuentren en el medio tienen la alternativa de poder negociar en los mercados libres. Como señalan Sanchis Palacio y Amigo Pérez (2018), la EBC tiene el objetivo de educar en valores éticos y sociales y es de gran interés su aplicación en diversos contextos como en la educación, y poder brindar a estudiantes y profesionales de organizaciones diversas opciones al modelo imperante. Verde-Diego et al. (2018), ponen ejemplos de varias empresas privadas como Action Waterscapes S.L., Ética de Patrimonios o VAUDE Sport GmbH \& Co.KG (Alemania), que se han transformado en propulsores de la EBC, creando un impacto positivo en la sociedad mediante sus proyectos.

La EBC es un modelo económico integral y global ya que se puede afirmar que es un referente relevante en los procesos de cambio económico a tres niveles: macro, meso y microeconómico; al mismo tiempo, está influyendo y predominando en heterogéneos escenarios económicos y tanto sus principios, ética y valores están llegando al sector social, financiero o empresarial (Campos, 2016 y Gómez y Gómez-Álvarez, 2016). Señalar que se trata de un modelo adaptable a todo tipo de organizaciones.

En este sistema económico alternativo, la satisfacción de las necesidades prevalece a la obtención de dinero. Éste, tal y como señala Felber (2012), puede ser un medio para satisfacer las necesidades, pero no ser el objetivo básico ${ }^{3}$ y, en lo alusivo a la política salarial, existen unas desigualdades enormes respecto a los salarios que ganan los altos ejecutivos en comparación con el salario mínimo legal. Por ello, este modelo económico establece unos parámetros y escalas salariales con las que pretende prohibir por ley estas diferencias. Triodos Bank un banco europeo independiente, es el que acata mejor los postulados de la EBC y, únicamente, financia a empresas, organizaciones e iniciativas rentables, mejoran la calidad de vida de las personas y amparan el medio ambiente.

La EBC busca garantizar que la dignidad, la solidaridad, la justicia social, la sostenibilidad ecológica, la transparencia y participación democrática estén presentes en todas las relaciones instauradas entre las personas y organizaciones (Felber, 2012). Con respecto a la equidad y justicia social, objeto del presente trabajo, señalar que el primer concepto posee heterogéneas acepciones, con un bagaje de interpretaciones diferentes según la disciplina de la que provenga; no obstante, todos los puntos de vista poseen un denominador común y es vincular la equidad a la justicia. Los valores actuales amparan la igualdad como un derecho de la ciudadanía. La equidad social, por lo general, hace alusión a disimiles ámbitos, como justicia social, derechos, libertades, igualdad de oportunidades, entre otros. Por su parte, la justicia social hace referencia a las nociones esenciales de igualdad de oportunidades y de derechos humanos, comprendidos más allá del concepto tradicional de justicia legal (ONU, 2006).

El hecho que surjan otros tipos de modelos económicos es de gran interés para todos, especialmente considerando que la economía es una ciencia que implica la satisfacción de necesidades del sujeto y del bienestar social y, tal y como se ha referido, en los últimos tiempos es notoria la insatisfacción por parte de la sociedad hacia la economía actual.

Por todo lo explicitado entendemos que un análisis sobre una parte tan concreta de la Economía del Bien Común como son los salarios, un indicativo de la capacidad de generar satisfacción de un modelo económico y especialmente de distribuir equidad y una retribución justa, es suficiente motivo para desarrollar este trabajo y justifica la investigación. Entendemos que cualquier modelo económico debe tener como fin el mayor beneficio para los miembros de la sociedad y evaluar dichos beneficios 
no sobre cantidades monetarias sino sobre los bienes sociales que proporciona a la comunidad, lo cual nos lleva a los objetivos de este trabajo.

El presente trabajo tiene como objetivos específicos analizar las escalas salariales que la EBC plantea a partir de ciertos indicadores y premisas para lograr una retribución justa y, por otro lado, examina las aportaciones que hace a los valores universales de la equidad y la justicia social. La metodología que se ha usado para la elaboración de este artículo ha sido mediante un estudio teórico, llevado a cabo principalmente a partir de la recopilación de múltiples textos fundadores de este campo y de la revisión de fuentes documentales (artículos, libros y revistas especializadas, publicaciones de organizaciones solidarias, informes de instituciones gubernamentales, entre otros.) secundando una estructura que faculta la exposición de las ideas desarrolladas en los apartados. Las búsquedas se han realizado en diferentes bases de datos como Google académico, con las palabras claves referidas, tanto en castellano como en inglés, con el fin de obtener documentos e informes académicos importantes y veraces. Además, se ha ejecutado un análisis sistematizado de todos los documentos hallados para de este modo concretar la información más importante para nuestro objeto de estudio. Para el análisis de las escalas salariales, se ha compilado y revisado el Manual del bien Común 5.0, así como revisado otros estudios e informes para poner en antecedentes la situación salarial en Europa y, con ello, ver la relevancia de las medidas expuestas por el modelo. Éste puede llegar a ser una opción al desarrollo económico, social, político y cultural, siendo un modelo abierto y en construcción. Al principio del estudio/cuerpo del trabajo se presenta una aproximación a los conceptos generales de la EBC. Posteriormente, se lleva a cabo una valoración de los beneficios que aporta y su complementariedad con la responsabilidad social empresarial y, por último, se desarrolla el tema central del trabajo, las escalas salariales. Para finalizar, se realiza un resumen y una conclusión con el cometido de compilar y analizar todos los conceptos e ideas expuestas.

\section{La economía de bien común: un modelo alternativo}

La EBC hace referencia a un sistema económico particularizado por concebir que la economía tiene como objetivo el incremento del bienestar de los sujetos o "bien común" y no la maximización de la riqueza ni el incremento de la misma. Por lo tanto, se puede aseverar que se trata de un modelo alternativo a la economía planificada y al capitalismo, un planteamiento económico y social dirigido a las personas que se manifiesta en las esferas económica, social y política. En esta línea, la EBC comenzó a popularizarse a raíz del libro $L a$ Economía del bien común publicado en 2012 por Felber, fundador también de Economy for the Common Good. Por otro lado, en el modelo de la EBC existen herramientas de medidas específicas y de fácil aplicación, como el Balance del Bien Común (BBC) la Matriz del Bien Común (MBC) y el Producto del Bien Común (PBC). Los dos primeros instrumentos son efectivas contribuciones practicas a nivel microeconómico y el último, el PBC, a nivel macroeconómico.

\section{- El Balance del Bien Común (BBC)}

El informe que recoge toda la información pormenorizada es el BBC y el resumen de dicha evaluación a través una única tabla se denomina MBC. La finalidad del BBC es computar el bien común de cualquier actividad humana. En él se integran criterios medibles en los alusivo a los ya mencionados valores universales (dignidad humana, solidaridad y justicia, sostenibilidad medioambiental, transparencia y participación democrática) involucrados en la actividad de la organización (término genérico que se usa igualmente para emprendedores/as) (Gómez-Álvarez, Morales Sánchez y Rodríguez Morilla, 2017). De este modo, cuanto más alto sea el nivel de dichos valores mejores serán los resultados del BBC logrados y mejorando los resultados de las organizaciones en una economía nacional, mejorará al unísono el Producto del Bien Común (PBC).

La EBC ofrece dos caminos distintos, es decir, uno en el que puedes simpatizar con sus postulados y otro, como empresa pionera certificada que cumple con todas las normas exigidas por dicha economía y, en este caso, existen ciertos requisitos de adhesión que se basan según sea el nivel de compromiso, el reconocimiento externo, así como el mecanismo de control. Existen tres viables niveles para la puesta en marcha del BBC:

1. Semilla: Las empresas que realizan el balance de forma interna, sin ser verificado y que no lo podrán publicar. 2. Semillas: Es la categoría para las empresas que lo hayan realizado y lo verifiquen por medio de una auditoria Peer (en grupo de dos empresas mínimo), pudiendo ser publicado. 3. Semillas: Esta categoría es para las empresas que realicen el balance (idealmente con un grupo de empresas) y éste sea auditado por un Auditor/a externo/a, pudiendo ser publicado finalmente (Aracil, 2012, p.6). 
Las organizaciones que quieran formar parte del proceso de la EBC tendrán que formar parte de la Asociación y con ello obtendrán las conexiones y las sinergias con otras organizaciones adheridas. Las empresas que obtengan los mejores resultados en el balance tendrán ventajas legales y beneficios que les ayudará en sus costes y podrán ofrecer productos éticos a precios más reducidos que los no éticos (créditos con interés más bajo, aranceles ventajosos, programas de investigación o prioridad y privilegios en la adquisición pública, por ejemplo). Los indicadores que conforman este balance miden el modo en que la empresa fomenta dichos valores en el momento de vincularse con proveedores, financiadores, trabajadores/propietarios, clientes/otras empresas o productos y servicios y ámbito social (región, soberanía generaciones futuras, personas y naturaleza) (Aracil, 2012; Rodríguez, 2018).

El BBC se ejecuta paralelamente a la forma tradicional del balance contable, no obstante, su medición se manifiesta en objetivos reflejados en la MBC (Amigo y Ribera, 2018). En suma, en la EBC, el modelo se basa en usar unos indicadores que ponen el punto de interés hacia los Stakeholders cruzándolos con los valores expuestos que son aplicables para la consecución del bien común (Lozano, Raufflet y GonzálezEsteban, 2018).

\section{Los beneficios de la EBC y la Responsabilidad Social Empresarial (RSE)}

La EBC fija nuevos roles de juego, un nuevo contexto, con la finalidad de maximizar el bien común para todos y no únicamente para el interés propio. Por lo tanto, para la supervivencia y éxito de las organizaciones, ya no se verán obligadas a tener como prioridad la competencia o confrontación con otras entidades, sino que su objetivo será la cooperación. Hoy en día, las empresas se ven ubicadas en una situación frágil en el mercado por causa de aquellos que ejercen la concentración y el abuso de poder como, por ejemplo, con los acuerdos de precios, puertas giratorias, los trabajos precarios, los salarios bajos o la corrupción. Ante esto, es necesario un sistema más equitativo, más ético, en el que se incentiven a las empresas que acaten los principios del bien común. La EBC promueve el éxito que tenga una empresa a partir del BBC, ya que el Balance Financiero tradicional no refleja de modo fiable las condiciones de los trabajadores, la explotación de los mismos o los sueldos precarios, en definitiva, las condiciones laborales en su totalidad. Adicionalmente, se han ido añadiendo a este proyecto económico varias propuestas con el objetivo de evitar el establecimiento de escoyos que imposibiliten el ejercicio real de las libertades, eludir también la acumulación de capital o para que la maximización del beneficio no sea el principal objetivo de la organización. Para ello, el propio Felber (2012) expone que están prohibidas actuaciones como la disociación de poder y responsabilidad, la repartición de ganancias entre propietarios que no trabajen en la organización y la concentración del poder económico. Por el contrario, presenta una serie de recursos permitidos de los beneficios: las provisiones para pérdidas, la cancelación de deudas, los préstamos sin intereses a trabajadores, proveedores o clientes o las inversiones con rentabilidad social. En esta línea, del reparto de las ganancias que la empresa genera, únicamente, pueden beneficiarse los sujetos que trabajan en la misma y, también, se fija un salario mínimo y máximo como un estímulo a la responsabilidad y al esfuerzo y, asimismo, que sirva como límite al acopio de riqueza; agregando a todo ello una "dote democrática" que todos los individuos, en el principio de su vida laboral, obtendrán como un incentivo para favorecer la verdadera equidad de oportunidades (Gómez y Gómez-Álvarez, 2016).

La RSE, bajo un enfoque colaborativo y multi-stakeholder, contiene decisiones que tercian en la organización a medio y largo plazo y, por lo tanto, dichas decisiones deben realizarse con todos los agentes involucrados en la gestión de la misma y no exclusivamente por los directivos. Asimismo se establecen políticas redistributivas en las organizaciones para alcanzar un reparto real y equitativo de los excedentes en base al valor y el riesgo que cada uno de los integrantes contribuye y asume (Felber, 2015).

Para Juergens (2018), el creciente modelo de la RSE que rige una conducta cooperativa puede complementarse con la EBC, de la cual señala que busca la erradicación de la concentración y el mal uso del poder y la ineficiente fijación de precios que derivan de los errores del capitalismo y la competencia. Para este autor, la EBC debe crear una conexión entre los valores que priman en los negocios y aquellos que posee lo social, al recompensar a las organizaciones en el fomento de valores como el mutuo aprecio, la cooperación, la confianza o la solidaridad.

A principios de 2019, Campos, Sanchis y Ejarque (2019) publicaron un estudio a nivel internacional sobre la EBC, en el cual se analizaron 657 empresas europeas (74 españolas) emplazadas en 12 países europeos, las cuales a 31 de diciembre de 2017 estaban implementando la EBC a distintos niveles. El objetivo era demostrar que la $\mathrm{MBC}$ es un instrumento de medida eficiente para la viabilidad social, económica y medioambiental de una organización. Según este estudio, las empresas españolas adheridas a la EBC superan el $11 \%$ del total de las europeas. Por lo tanto, España gana a países como Italia y Suiza que tienen un cierto grado de implementación del modelo con un 4,26\% y un 2,13\%, respectivamente. Evidentemente, Alemania que supera el $45 \%$ o Austria, con más del 35\%, son los países que encabezan el ranking por ser donde nació y desarrolló el modelo. El estudio ha facultado obtener una información muy 
valiosa: para empezar, acerca de aspectos generales y características de las organizaciones (el país de origen, los datos de facturación, la actividad, el sector económico, año de creación, etc.). Por otra parte, aspectos vinculados con la labor que lleva a cabo la entidad en vinculación con la EBC como, por ejemplo, el grado de implementación del $\mathrm{BBC}^{4}$ y de los principios del modelo económico y, también, las predicciones de futuro de aplicación del balance; y, por último, aporta la información en relación a las puntaciones obtenidas de cada variable de la MBC. El estudio muestra que las organizaciones analizadas se particularizan en ser mayormente empresas del sector servicios, científicas y técnicas y, concretamente, dedicadas a actividades de gestión empresarial y de consultoría; se trata de entidades jóvenes, creadas a partir de principio del siglo XXI y de pequeña dimensión, ya sea en el número de empleados como en la facturación, es decir, microempresas. ${ }^{5}$ Se indican los componentes en los que las empresas más han mejorado con la anexión a la ECB y son los siguientes: en el control del comportamiento ético de los bancos, en el aumento de las inversiones responsables (fomento de la banca ética y social), en la proporción de suministros sostenibles certificados, en el clima laboral, en relación directa y personal con sus clientes y en la satisfacción con las necesidades de los mismos, en la reputación corporativa, en las relaciones entre los empleados y en el grado de motivación y bienestar de los trabajadores. No obstante, también explica la otra cara de la moneda, puesto que, respecto a la inserción sociolaboral, concretamente de personas con diversidad funcional y del municipio, se evidencia que están en situación de inferioridad. Del mismo modo, padecen este escenario las mujeres en los órganos de gestión y otros aspectos como el impacto medioambiental y el patrocinio de actividades locales, que no tuvieron en este estudio empírico los resultados positivos de las primeras variables mencionadas.

\section{La propuesta de la EBC en las escalas salariales}

La EBC propone fijar unos nuevos indicadores económicos fundamentados en la justicia social que trasciendan al PIB (Felber, 2015). La justicia social está fundamentada en la igualdad y en una distribución ecuánime de la riqueza necesaria para que todo ser humano pueda llevar a cabo su máximo potencial. El triunfo de la materialización del bien común se da, de forma triunfante, en una sociedad en el momento en el que la justicia e igualdad social convergen en un único objetivo. Éste se debe posicionar en la defensa del sujeto como una máxima frente a la construcción del propio Estado. Las desigualdades económicas derivan en desigualdades políticas y éstas, al unísono, provocan desigualdades sociales, es decir, todas se retroalimentan. Como señala la ONU, la justicia social:

Es un principio fundamental para la convivencia pacífica y próspera, dentro y entre las naciones. Defendemos los principios de justicia social cuando promovemos la igualdad de género o los derechos de los pueblos indígenas y de los migrantes. Promovemos la justicia social cuando eliminamos las barreras que enfrentan las personas por motivos de género, edad, raza, etnia, religión, cultura o discapacidad (Documento de la ONU, 2006, en: Gómez-Álvarez Díaz, Morales Sánchez y Rodríguez Morilla, 2017, p.200).

La EBC incluye ciertos requisitos básicos como la equidad y la justicia social, puesto que los ciudadanos deben proporcionarse unos a otros derechos y libertades básicas y no deben explotarse mutuamente. Pero este postulado va más allá de los requisitos básicos de la justicia porque requiere que las personas mantengan ciertos modelos de conducta con el argumento de que dichos patrones sirven a ciertos intereses comunes. En el ámbito empresarial, puede implicar una vulneración de los derechos humanos aquellas retribuciones salariales que no sean equitativas o que no garanticen a los empleados unos medios de existencia dignos para ellos y su familia.

Uno de los aspectos económicos de primera magnitud en el mundo es la desigualdad salarial ya que contiene dos factores en términos de eficiencia, por un lado, es un problema significativo en la marcha del mercado laboral y, por otra parte, en lo que respecta a la igualdad, al ser un condicionante esencial de la distribución de la renta y su progreso en el tiempo, terciando en la diferencia de los salarios y, por ende, en la cohesión social. Además, como señala la OCDE en 2011, buena parte de la diferencia de los ingresos en las economías occidentales se debe a la diferencia salarial y la mayor parte de los cambios en la distribución de la renta se origina por las variaciones que se dan en los ingresos salariales, si bien, obviamente el aumento de

(red de pares, balance interno, y auditado externamente).

“(...) la mitad de las empresas EBC españolas tienen menos de 10 trabajadores, es decir, son microempresas, más de las tres cuartas partes tienen menos de 50 trabajadores, es decir, son pequeñas empresas, y casi el $90 \%$ tienen menos de 250 trabajadores, es decir, son Pymes. Solo el $12,5 \%$ de las empresas tienen más de 250 trabajadores. se compara con la media en Europa, se puede decir que las empresas EBC españolas tienen un tamaño algo superior, pues solo el 7,7\% de las empresas EBC de Europa tienen más de 250 trabajadores y casi el $56 \%$ son microempresas (6 puntos más que las españolas)" (Campos, Sanchis y Ejarque, 2019, p. 8-9). 
las desigualdades de las rentas en los hogares no se debe exclusivamente a este único factor, aunque cuando hablamos de igualdad social, las diferencia salarial es un elemento fundamental y tiene un enorme influjo en la prevalencia e incidencia de la pobreza.

El grado de desigualdad salarial es distinto entre países y normalmente oscila con el transcurrir de los años a consecuencia de diversas y heterogéneas causas. Es más, durante los últimos tiempos, en los países desarrollados se han producido cambios que han incidido en mayor o menor grado a las distribuciones salariales. Entre ellos podemos encontrar el incremento de los extranjeros en los mercados de bienes y servicios, la mayor desregularización y terciarización del trabajo, la feminización del mercado laboral, el aumento de la inmigración o el incremento a nivel educativo. A la par de estas transformaciones se han trastocado condiciones macroeconómicas y contextos del mercado laboral, como puedan ser la merma de la sindicación de los trabajadores, la flexibilización de las relaciones laborales o la descentralización de la negociación colectiva (Antonczyk et al., 2010).

La Confederación Europea de Sindicatos (CES) ha publicado el informe Benchmarking Working Europe $2019^{6}$ en el que se coteja los salarios en Europa en base a las particularidades de las organizaciones y los trabajadores. Se trata de un informe anual que estudia la sostenibilidad del crecimiento económico, la recuperación, la cantidad y calidad del empleo, entre otros factores. De acuerdo con el mismo, la cantidad de sujetos que poseen, actualmente, un trabajo es equitativa a los niveles precedentes a la crisis, aunque los empleos y los trabajadores han cambiado. Por ejemplo, el nivel de logro educativo entre los empleados se ha incrementado, pero no así la calidad de los puestos de trabajo. Uno de los datos más destacables es el que reporta que la recuperación de la economía se debe a la expansión de múltiples formas de empleo no "convencional", como el trabajo temporal, la subcontratación o los de corta duración y, además, afirma que esta situación implica múltiples peligros para los trabajadores entre los cuales se encuentran las desigualdades sociales y la pobreza laboral. Es más, se señala que tras un lustro de crecimiento económico ha aumentado la desigualdad salarial, más trabajadores que nunca tienen contratados laborales con condiciones estándares y el porcentaje de empleados pobres continúa estando por encima de su nivel anterior a la crisis, sin duda datos más que preocupantes.

España es uno de los países donde se evidencia una mayor reducción salarial que la media y ostenta una de las mayores tasas de temporalidad, la cual alcanza el 85,2\%. En Chipre, los trabajadores temporales son el 91, 9\%. Rumania y Portugal también encabezan esta lista. España presenta un balance especialmente negativo en los que se refiere a la evolución salarial, emplazándose en el tercer país europeo por diferencial negativo de los salarios reales en comparación con la productividad, en concreto 15 puntos porcentuales en la última década. En 2018, no hubo cambios y continuó a la baja la evolución de los salarios con una merma del $0,7 \%$.

Figura. 1. Evolución de los salarios reales entre 2009-2018 (\%).

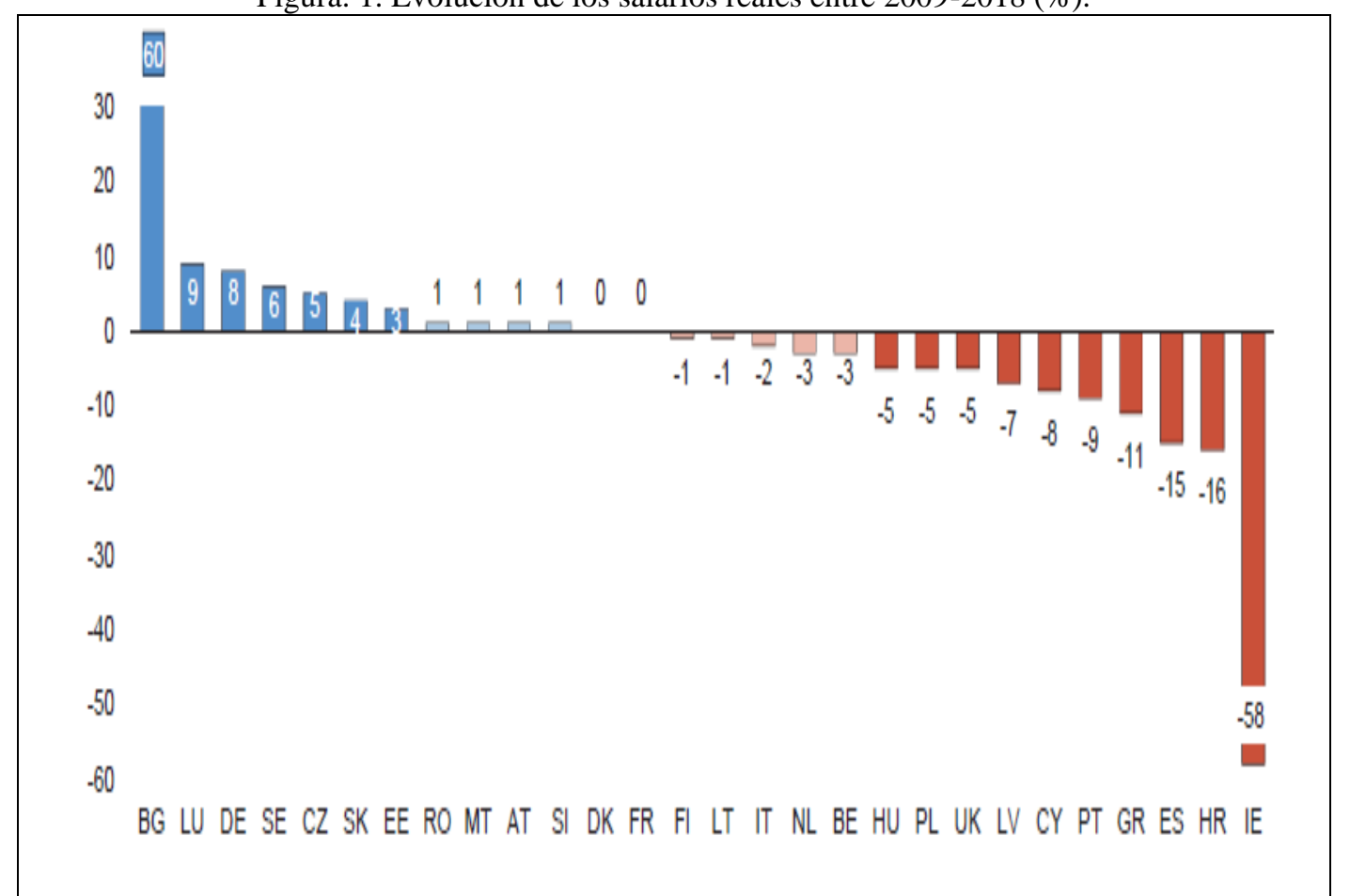

6 (Análisis comparativo de la Europa trabajadora) 
Fuente: Benchmarking Working Europe (2019, p.51).

Figura. 2. Desarrollo de los salarios nominales y reales y la productividad en 2018 (cambio en \% en comparación con 2017).

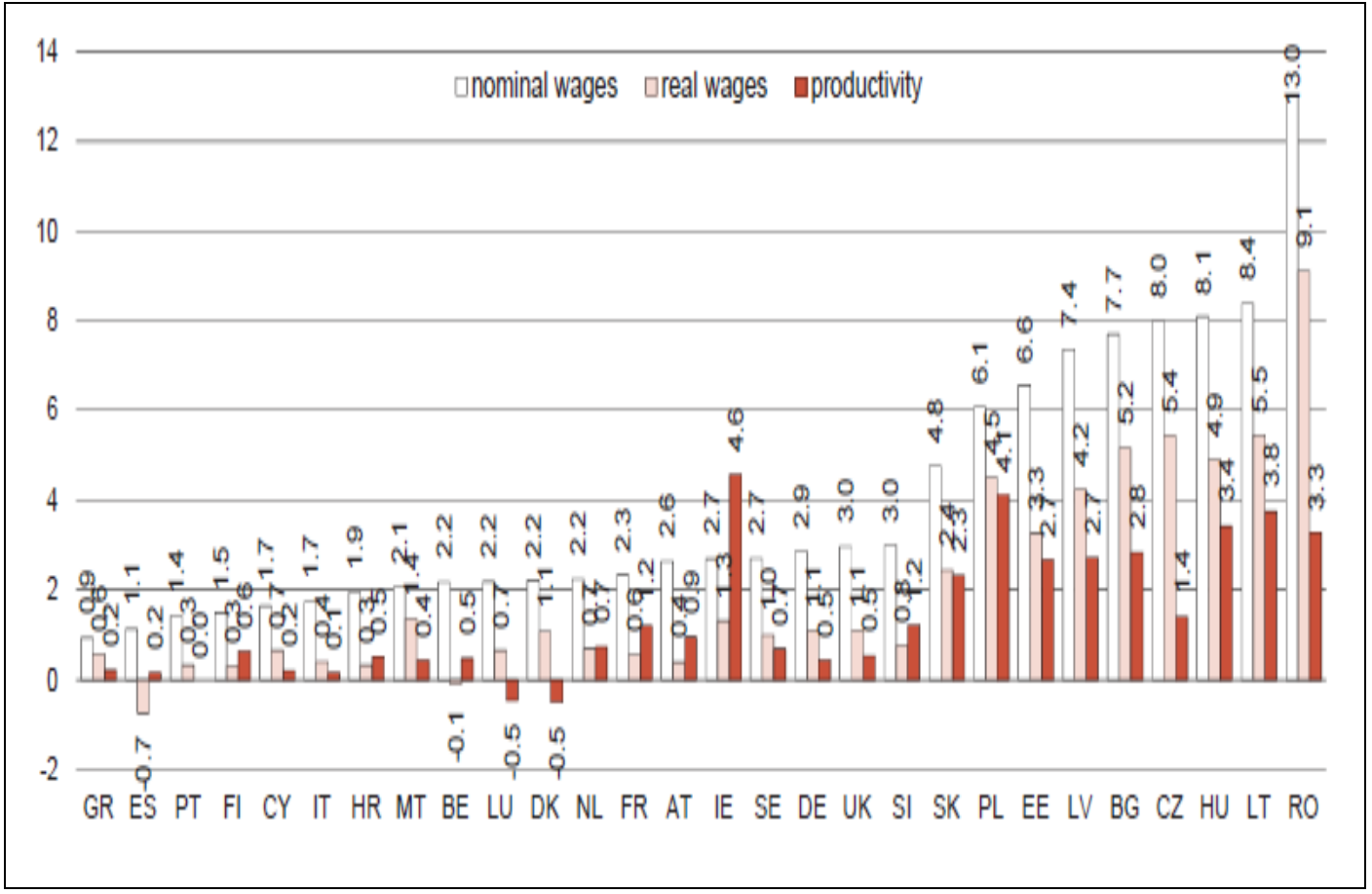

Fuente: Benchmarking Working Europe (2019, p.49).

Los salarios en el caso de España, como en otros países, pierden peso en la composición del PIB, concretamente 5 puntos porcentuales en la última década.

Para Felber, el hecho de que el mejor ejecutivo de los EE.UU. cobre 350.000 veces el salario mínimo legal no tiene relación con una "política de precios racional", ni con la justicia ni eficacia, simplemente lo asocia al poder, a la economía del mercado. Una de las causas de las desigualdades y la brecha entre ricos y pobres es la "libre competencia". Ésta, sin embargo, como apunta el profesor, provoca miedo, mientras que la cooperación lo que pretende es lograr una meta igual (Felber, 2012). Por lo tanto, propone en el BBC, que cada organización tiene la opción de evaluar cuantitativamente cual ha sido su aportación al bien común para cada uno de los indicadores; todos los criterios suman un total de 1.000 puntos, es decir, es la puntuación máxima que se puede lograr. Los valores universales que ya se han señalado, dan lugar a una serie de indicadores, que a su vez se utilizan en 4 niveles: principiante, avanzado, experimentado y ejemplar. Dichos niveles facultan, a la hora de evaluar el resultado, un mayor detalle y concreción de cada indicador. En el apartado de "Características de los contratos de trabajo" del BBC se expone que:

Los contratos de trabajo regulan la cooperación entre la organización y las personas empleadas. Los contratos y la asignación de recursos como la remuneración, tiempo, seguridad o medidas de conciliación tienen una influencia considerable sobre las personas empleadas en su disposición a trabajar, su sensación de seguridad, y su bienestar. El objetivo es disponer de contratos de trabajo que se ajusten a las necesidades individuales y que sean diseñados con las mismas personas empleadas. (BBC, 2017, p.55)

Y en el subapartado de la remuneración se establece que: (BBC, 2017, p.55)

Menos en los casos en que sea señalado de otra manera, entendemos por remuneración, la remuneración bruta mensual. En países u organizaciones en las que existan más de 12 pagas, deben repartirse las pagas extraordinarias de manera proporcional. Consideramos remuneración cualquier pago en dinero o en especie, que surge de la organización a la persona empleada. Dentro de estos pagos se encuentran:

- Pagos fijos y variables.

- Pagas extras.

- Bonos. 
- Reparto de beneficios.

- Prestaciones sociales voluntarias.

En el balance se indica que la remuneración más alta y más baja engloba a todos los trabajadores los cuales los define como "las personas cuya actividad es esencial para la organización (= esencial para la actividad de la organización). Forman parte del espacio y de la estructura organizativa y social de la organización en uno de los siguientes ámbitos:

- Relación laboral contractual

- Personas que trabajan con un contrato temporal durante un período de al menos seis meses

- Personas que trabajan con un contrato de al menos cuatro horas por semana

- Personas que trabajan con un contrato por obra o servicio de forma periódica y recurrente (por ejemplo, en la campaña de navidad y verano)" (BBC, 2017, p.12)

Asimismo, se indica que "la remuneración digna (o salario digno) no se corresponde con el salario mínimo. El salario digno debe determinarse para cada ubicación de la organización, de tal modo que se puedan considerar los costes de vida de cada región” (BBC, 2017, p.56-57).

Tabla. 1. Remuneración: niveles de valoración

Ejemplar: Se ha desarrollado un proceso para que cada persona empleada pueda fijar su remuneración. La remuneración se adapta caso a caso de acuerdo a las necesidades individuales y es fijado por las personas empleadas.

Experimentado: La razón entre la máxima y la mínima remuneración no supera 1:5. Esta razón puede ajustarse a las necesidades de la organización si es legitimada por todas las personas empleadas.

Avanzado: Se han implementado medidas para garantizar una remuneración digna acorde con los costes de vida de la región en la que se encuentra.

Primeros pasos: Análisis y diálogo periódico sobre una estructura salarial justa.

Punto de partida: Se cumple con las exigencias mínimas de la regulación (ej. salario mínimo)

Fuente: extraída de BBC (2017, p.56)

Respecto a los indicadores que deben ser obligatorios para la empresa se establecen los siguientes:

Tabla. 2. Indicadores obligatorios para los contratos de trabajo injustos.

- Salario digno para cada ubicación de la organización.

- Beneficios.

- Número de personas empleadas.

- Salario más alto y más bajo.

- Número de contratos "predeterminadoso" (sin adaptación a necesidades individuales).

- Cantidad de contratos zero-hour.

- Duración de contrato máxima y mínima de las personas empleadas temporales.

- Número de personas empleadas (incl. personas empleadas temporales)

- Número de personas empleadas temporales.

- Duración de los contratos de duración determinada.

- Porcentaje de contratos de duración determinada.

- Política (real) de renovación de contratos de duración determinada Fuente: BBC (2017, p.59)

Y en los que respecta a los niveles de valoración de dichos trabajos señala los siguientes requisitos:

Tabla. 3. Niveles de valoración incl. Puntuación.

- Salarios no dignos habiendo beneficios en la organización.

- Razón salarial mayor a 1:20.

- Pagos de salarios aplazados o retrasados con asiduidad. 
- Brecha salarial mayor del 10\% para trabajos similares - según género, etnia, edad, etc.

- Cláusulas predeterminadas según las cuales las horas extras se pagan automáticamente (en más del 10\% de los contratos).

- Contratos de duración determinada mayor a dos años o que durante ese espacio de tiempo han sido renovados más de dos veces.

- Trabajo temporal con una duración mayor a 6 meses o que representa más del $10 \%$ de los contratos.

- Contratos zero-hour.

Fuente: BBC (2017, p.60)

Como se expone en los 20 puntos centrales de la EBC, las organizaciones adscritas a la misma tendrán una serie de ventajas y beneficios como créditos baratos, impuestos reducidos, privilegios en las adquisiciones públicas, aranceles ventajosos y accesos a programas de investigación. El horario laboral irá mermando de forma escalonada hasta llegar a las 30 o 33 horas semanales y, además, el empleado disfrutará de un año de excedencia cada década que lleve en la entidad el cual se financiará mediante un salario mínimo incondicional. Los salarios máximos tendrán sus restricciones, es decir, no podrán sobrepasar 20 veces a los mínimos. ${ }^{7}$

La brecha salarial entre las potencias económicas europeas, a pesar de las recomendaciones de las instituciones de la UE y las medidas y normas llevadas a cabo por los Estados, han disminuido a niveles muy bajos en los últimos años. En España, según la Confederación Española de Organizaciones Empresariales (CEDE) en 2019, la brecha salarial entre sexos (ajustada) sobrepasa el 12\%; las mujeres cobran un 12,2\% menos que los hombres. Según el informe "Women in Business" realizado por Lagerberg (2017), la conciliación de la vida personal y profesional no son suficientes para que no se produzca esta situación. La EBC lucha contra cualquier tipo de desigualdad salarial.

Para Mora, López y Hilliard (2018), las discrepancias salariales que se originan en aquellas empresas que se rigen por la EBC tendrían que ser objeto de un debate público que permitiera democráticamente pactar la brecha salarial máxima permitida en una sociedad. También indican que usar los precios de mercado con el fin de valorar el peso de los empleados implica, al ejecutarlo sin ningún tipo de excepciones ni connotaciones, dar por sentado las desigualdades de salarios existentes.

Señalar que el punto de debate más en auge en la economía actual son las ganancias de una empresa. Para la EBC, las ganancias corporativas se distribuirá o reinvertirá de la manera más justa y equitativa posible, promoviendo el bien común al más alto nivel de justicia social. ${ }^{8}$ Para enfrentar mejor este desafiante cambio de mentalidad, el EBC plantea las siguientes cuestiones fundamentales que toda la sociedad debería tener en cuenta; éstas son: ¿Cuál es el propósito de una empresa?; ¿Qué significa desempeño y logro para nosotros/as?; En principio, ¿debería el crecimiento del capital ser un reclamo natural?; ¿Qué impactos sistémicos tiene el ROI (por sus siglas en inglés, «Retorno Sobre la Inversión») (Gonçalves, 2015).

Se ha referido que las desigualdades en los salarios se originan en aquellas empresas contrarias a los postulados de la ECB. Ésta ampara que dichas brechas salariales tendrían que constituir parte de un debate público. Este modelo pretende la reducción de las desigualdades de ingresos, un sueldo básico garantizado y limitaciones a la especulación financiera, logrando con ello una equidad y justicia social, bases esenciales del bien común (Stumpf y Sommer, 2019). En definitiva, para lograr justicia y equidad social, la EBC plantea unos objetivos e indicadores específicos como parámetros iniciales para establecer una mayor discusión democrática. Con ello, el desempleo se estima bastante improbable, puesto que la reducción de la fuerza laboral como elemento de maximización de ganancias ya no tiene sentido y, asimismo, la presión excesiva de trabajo tendría consecuencias negativas en el equilibrio del bien común.

Puntos centrales de la EBC (punto 8):

Las diferencias de ingresos y patrimonios serán limitadas: Ingresos máximos de por ejemplo 20 veces el salario mínimo. Propiedades que no excederán p. ej. los 10 millones de euros, el derecho de cesión y herencia, 500.000 euros por persona, en empresas familiares a 10 millones de euros por hijo. El excedente sobre estos límites será repartido a través de un "fondo de generaciones" como "Dote democrático" a las siguientes generaciones: igualdad de capital inicial significa mayor igualdad de oportunidades. (Los márgenes exactos deberán ser definidos democráticamente en una asamblea económica) (Fuente: portal de la EBC).

Puntos centrales de la EBC (punto 3):

El éxito económico no es medido por indicadores monetarios como el beneficio financiero o el BIP, sino con el balance del bien común (a nivel de empresas) y el producto del bien común (a nivel de sistema). El balance del bien común se convierte en el balance principal de todas las empresas. Cuanto más social, ecológica, democrática y solidaria sea la actividad, mejores serán los resultados del balance del bien común alcanzados. Mejorando los resultados del balance del bien común de las empresas en una economía nacional, mejorará el producto del bien común (Fuente: portal de la EBC) (Fuente: portal de la EBC). 


\section{Resumen y conclusiones}

La EBC germina y se desarrolla en un periodo de recesión a nivel global caracterizado por muchos factores, entre otros, un reparto de la riqueza y de las oportunidades disímiles, una crisis de valores, el cambio climático, un elevado nivel de paro o un elevado consumismo. Debido a la existencia de crisis sistémicas, este modelo está expandiéndose en distintos países. La propuesta más relevante de este postulado es que la economía debe estar al servicio de la ciudadanía y esto es que el capital y el dinero tienen relevancia como herramientas de inversión o de intercambio, si bien, no son un fin por sí mismos.

La EBC aspira a ser un modelo económico alternativo al capitalismo y una de sus contribuciones más notables es trasladar a las organizaciones de capitales los valores que gobiernan el comportamiento de las empresas sociales, logrando que dichas organizaciones incrementen su compromiso social con los postulados del modelo. Su éxito reside en que expone unas bases y unas ideas sencillas de conseguir, con pequeños avances, sin unos requisitos inalcanzables. Sin embargo, se ha de tener presente que estamos hablando de un modelo económico reciente y con establecimiento aún limitado que hace dificultoso una estimación real de su nivel de impacto y consecuencias. Los partidarios de este movimiento reconocen que se trata de un proceso dinámico y abierto, el cual se irá nutriendo y precisando a medida que se desarrolle. Además, la EBC se instaura dentro de una economía de mercado que acepta, pero no así las normas y reglas con la que se rige (la avaricia, el afán de lucro, la irresponsabilidad o la competencia, por ejemplo).

El modelo de EBC permite resaltar valores como la justicia, la solidaridad, la responsabilidad y el respeto con el medio ambiente, y de la toma de conciencia de dichos valores aparece el pensamiento que la economía está formada por varios factores y que no, únicamente, se ha de considerar el capital, el mercado o los elementos de producción, sino que las personas son parte de la economía y ésta debe ser más equitativa en la repartición de la riqueza, más mas social, ecológica, más justa y democrática.

La aplicación de este modelo tanto para la sociedad en general como para las empresas en particular puede dar resultados eficaces y positivos, aplicado los cuatro valores básicos y, a su vez, gracias a las acciones de las entidades muchos gobiernos pueden destinar el dinero ahorrado en gastos para otras funciones como pagar menos impuestos, mejorar la educación o la sanidad.

El modelo permite aplicarse a todo tipo de entidades mediante el BBC y esto sin duda es una gran ventaja, al contrario de otros enfoques como la Economía Social y Cooperativa que se encauzan en concretos tipos de organizaciones. Hoy en día, son múltiples y heterogéneas las empresas que lo están instaurando, como empresas públicas, municipios, universidades o empresas privadas.

Como el objetivo de la EBC es la satisfacción de las necesidades de las personas en vez del lucro, se ha tachado al modelo de poco real o utópico. No obstante, el dinero no debe ser el objetivo primordial sino un medio para satisfacer las necesidades básicas, y además una empresa con éxito debe ganar lo suficiente para que sus trabajadores ganen lo que precisan para poder cubrir dichas necesidades con sus salarios.

Las desigualdades salariales son enormes y han sido un problema histórico y existente en todos los países del mundo. Para la EBC, la solución estriba en transformar el concepto de éxito empresarial, ya que ciertos indicadores con los que se mide el éxito, como el económico o el financiero, no se puede calcular si la economía está alcanzando las necesidades básicas y humanas imprescindibles para las personas, mientras que con la EBC y su balance de resultados si se puede conocer esta circunstancia y poner soluciones en el caso de no cumplirse.

Se puede determinar que la EBC puede ser muy beneficiosa para una organización y una economía de todos, ya que tienen multitud de factores eficaces y necesarios, si bien, se precisa que los valores que postula sean puestos en práctica e irlos aplicándolos progresivamente. Es necesario encontrar actores ya existentes que respalden este sistema económico y que la sociedad crea y vea en el mismo un futuro para, ulteriormente, desarrollarlo plenamente en el mundo empresarial y en otros muchos ámbitos. Las empresas que se rigen por este modelo, tanto desde la perspectiva interna como externa son socialmente responsables.

En suma, el artículo analiza las escalas salariales y planteamientos que propone para ellas, además de exponer la relevancia que para este tipo de economía tiene los valores de equidad y justicia social. De este modo, internamente los principios que gobiernan son la transparencia, los democráticos y la equidad retributiva con escalas salariales muy igualitarias. Una vez hecho el análisis de los principios que se emplean en la ECB y el análisis de las escalas salariales, se puede concluir que sus postulados no distan mucho de los fundamentos de la escuela clásica, es decir, este modelo pretende volver, si bien, con ciertas actualizaciones, a los valores iniciales de la escuela clásica. La mayor diferencia entre ambos enfoques estriba en que el objetivo principal de la EBC es poner a las personas y la relación entre las mismas y la empresa como meta principal y no la obtención de beneficio. El situar a la persona en la primera posición después de la obtención de riqueza personal producirá más beneficios para la organización, hecho que se ha evidenciado en empresas que llevan practicando este modelo económico. Si las organizaciones pagaran menos impuestos por favorecer al trabajador, habría una estimable merma del desempleo e incluso pensiones garantizadas lo cual podría conducir a un sistema eficaz en el que la economía en vez de fundamentarse en la competencia lo que 
hiciera fuera recoger los beneficios de la cooperación. Es evidente que la EBC es un modelo reciente, abierto $\mathrm{y}$, como se ha expuesto, equitativo, democrático e igualitario, amparando los derechos humanos.

\section{Referencias bibliográficas}

Amigo, M.; Ribera, M. (2018). El Balance del Bien Común. En: Sanchis, J. R.; Amigo, M. (coord.). El modelo de la Economía del Bien Común. Aplicación en la empresa/organización y casos prácticos, Madrid: Delta Publicaciones, pp. 121-140.

Antonczyk, D.; Fitzenberger, B. y Sommerfeld, K. (2010) Rising wage inequality, the decline of collective bargaining and the gender wage gap, Labour Economics, 17(5), 794-826.

Aracil, L. (2012) La economía del bien común: el reto del siglo XXI. Rev.: r Área de Innovación y Desarrollo, S.L. Recuperado de: https://www.3ciencias.com/wp-content/uploads/2012/09/4.-La-economia-del-bien-comun.pdf.

BBC (2017) Manual del balance del bien común 5.0 balance completo. Creative Commons. Recuperado de: https://economiadelbiencomun.org/wp-content/uploads/2018/10/Manual-Balance-Bien-Comun-2018-octubre-1.pdf.

Benchmarking Working Europe (2019). Ed: ETUI. Recuperado de: https://www.etui.org/Publications2/Books/Benchmarking-Working-Europe-2019.

Campos, V. (2016) La economía social y solidaria en el Siglo XXI: un concepto en evolución. Cooperativas, B corporations y economía del bien común, Oikonomics, Revista de Economía, Empresa y Sociedad, № 6, pp. 6-15.

Campos, V, Sanchis. J.R. y Ejarque, A. (2019) Social entrepreneurship and Economy for the Common Good: Study of their relationship through a bibliometric analysis. The International Journal of Entrepreneurship and Innovation. Recuperado: https://journals.sagepub.com/doi/10.1177/1465750319879632?icid=int.sj-abstract.citing-articles.2\&.

Campos, V. Sanchis, J.R. y Ejarque, A. (2019) El modelo de la Economía del Bien Común. Un estudio empírico sobre su aplicación a la empresa privada. REVESCO. Revista de Estudios Cooperativos, Tercer Cuatrimestre, $\mathrm{N}^{\circ} 132$, pp. 46-76. DOI: http://dx.doi.org/10.5209/REVE.64304.

CESE (2015) La Economía del Bien Común: un modelo económico sostenible orientado a la cohesión social, Dictamen del Comité Económico y Social Europeo sobre el tema 2016/C 013/16 de 17 de septiembre de 2015.

Compés López, R.; Asensio Calatayud, I. (2014) Economía del bien común y minifundismo en el sector agroalimentario: el caso del Celler La Muntanya (Alicante) y la marca. Revista Española de Estudios Agrosociales y Pesqueros, № 237, pp. 181-209.

Felber, C. (2012) La Economía del Bien Común. Barcelona: Grupo Planeta.

Felber, (2015) Change Everything. Creating an Economy for the Common Good. Editorial: Zed Books.

Felber, C. Campos, V. Sanchis, J.R. (2019) The Connom Good Balance Sheet, an Adequate Toll to Capture NonFinancials?, Sustainability. 11 (14) 3791.

Foti V. T. Scuderi, A., \& Timpanaro, G (2017) The economy of the common good: the expression of a new sustainable economic model. Quality - Access to Success Supplement 2, Vol. 18, pp. 206-214.

Gómez, V. y Gómez-Álvarez, R. (2016) La economía del bien común y la economía social y solidaria, ¿son teorías complementarias?, CIRIEC-España, Revista de Economía Pública, Social y Cooperativa, No 87, pp. 257-294.

Gómez-Álvarez Díaz, R., Morales Sánchez, R., Rodríguez Morilla, C. (2017) La Economía del Bien Común en el ámbito local. CIRIEC-España, Revista de Economía Pública, Social y Cooperativa, № 90, pp. 189-222.

Gonçalves, R.C. (2015) The 3rd International CSR Communication Conference. The Common Good Balance: Sustainability performance, measurable and comparable. Recuperado de: http://csrcom.org/img/upload/proceedings_za_objavo.pdf\#page=22.

Juergens, A. (2018) Fostering Client Altruism and the Common Good in the Practice of Law: Learning from Emerging Movements in Business and Economics. Mitchell Hamline L. Rev. 1 Recuperado de: https://open.mitchellhamline.edu/cgi/viewcontent.cgi?article=1091\&context=mhlr.

Lagerberg, F (2017) Women in business. Ed. Grant Thornton. Recuperado de: https://grantthornton.pl/wpcontent/uploads/2017/03/Grant-Thornton_Women-in-Business_2017-FINAL_Digital.pdf.

Lozano, J.; Raufflet, E. \& González-Esteban, E. (2018) Lecturas críticas de las nuevas propuestas de economía alternativa: ¿Qué hay de nuevo en lo nuevo?, Recerca. Revista de Pensament i Anàlisi, № 23, pp. 9-18.

Mora, A., López, C. y Hilliard, I. (2018) Evaluando los stakeholders de la Economía del Bien Común, CIRIEC-España, Revista de Economía Pública, Social y Cooperativa, No 94, pp. 251-283.

ONU (2006) Social Justice in an Open World: The Role of the United Nations, New York: ONU

Rodríguez, C. (2018) El modelo de la Economía del Bien Común: fundamentos teóricos. En: Sanchis, J. R.; Amigo, M. (coord.). El modelo de la Economía del Bien Común. Aplicación en la empresa/organización y casos prácticos, Madrid: Delta Publicaciones, pp. 3-18.

Sanchis, J. R.; Campos, V. (2018) Economía del Bien Común y Finanzas Éticas. CIRIEC-España, Revista de Economía Pública, Social y Cooperativa, № 93, pp. 241-264.

Sanchis Palacio, J. Ramón y Amigo Pérez, M. (Coord.) (2018) El modelo de la economía del bien común. Aplicación a la empresa/organización y casos prácticos. Madrid: Ediberum.

Stumpf, K y Sommer, B (2019) The Economy for the Common Good: a European countermovement against the destructive impacts of laissez-faire capitalism?, Culture, Practice \& Europeanization, Vol. 4, No. 1, pp. 103-115. 
Recuperado de: https://www.uni-flensburg.de/fileadmin/content/seminare/soziologie/dokumente/culture-practiceand-europeanization/cpe-vol.4-no.1/sommer-stumpf-cpe-2019-vol.4-nr1.pdf.

Verde-Diego, C. Sanchis Palacio, J. Ramón y Amigo Pérez, M. (Coord.) (2018) El modelo de la economía del bien común. Aplicación a la empresa/organización y casos prácticos. AZARBE, Revista Internacional De Trabajo Social Y Bienestar, (7), 67. Recuperado a partir de https://revistas.um.es/azarbe/article/view/355251. 